\title{
Jenaro Abasolo. Consideraciones socioeconómicas de un filósofo marginal del siglo XIX chileno
}

\author{
PABLO MARTÍNEZ BECERRA* \\ Universidad de Playa Ancha (Chile) \\ pablomartinezbecerra@yahoo.es \\ FRANCISCO CORDERO MORALES** \\ Universidad Tecnológica de Chile (Chile) \\ atremes@gmail.com
}

\begin{abstract}
Resumen
Este artículo trata sobre el filósofo chileno Jenaro Abasolo. Se expone en él, primeramente, la producción literaria de Abasolo y la nula receptividad que su obra tuvo en los círculos intelectuales de su tiempo, aludiendo, a la vez, al concepto central de su filosofía, es decir, la idea de personalidad. Luego, y más extensamente, se presentan las consideraciones de Abasolo respecto de algunas de las problemáticas sociales y económicas discutidas en los inicios de la República, abordando temas como la moral, la religión, el fin social y la libertad. Palabras clave: Abasolo, filosofía, personalidad, economía, sociedad.
\end{abstract}

\section{Jenaro Abasolo. Socioeconomic considerations of a marginal philosopher of the Chilean 19th century}

\begin{abstract}
This article is a treatise on the Chilean philosopher Jenaro Abasolo. Primarily, it exposes Abasolo, his literary production, and the complete lack of attention that his oeuvre recieved from the intellectual circles of his period. It alludes, at the same time, to the central concept of his philosophy, i.e., the idea of personality. Later and more extensively, it presents Abasolo's considerations regarding social and economic issues discussed at the beginning of the Republic, addressing topics such as morality, religion, social order and freedom.
\end{abstract}

Key words: Abasolo, philosophy, personality, economy, society.

\footnotetext{
* Doctor en Filosofía por la Universidad de Valencia (España). Actualmente se desempeña como profesor de la Facultad de Humanidades de la Universidad de Playa Ancha. Entre sus publicaciones cabe mencionar los libros Nietzsche y el despliegue de la libertad (2007) y Nietzsche, descenso a Dioniso y ascenso trágico (2008).

** Doctorando en Filosofía por la Pontificia Universidad Católica de Valparaíso. Profesor en las Universidades Tecnológica de Chile y Mayor. Autor del libro La creación díscola del mundo o la voluntad como fundamento metafísico en Schopenhauer (2007).
} 


\section{Introducción}

José Francisco Jenaro Abasolo Navarrete (Santiago 1833-1884) formó parte de la élite social del Chile decimonónico con facultad para decidir por los demás, es decir, integró ese escaso diez por ciento de la población que en el transcurso del siglo XIX —y aún después- rigió, en gran medida y en los ámbitos más variados, por «preceptos constitucionales y legales» (Salazar \& Pinto, 1999: 89), el destino del restante porcentaje de chilenos que no se ajustó a la categoría de ciudadanos. Sin embargo, Abasolo no alcanzó ninguna fama. Tanto así que la única noticia pública que existe sobre él, habla de su desempeño como funcionario del Estado en el Colegio de Minería de Copiapó ${ }^{1}$. De donde quizás la falta de figuración política de Abasolo explica, en parte, el que no se le reconociera su condición de pensador ${ }^{2}$. Esto a diferencia de nombres como los de Juan Egaña, Andrés Bello, José Victorino Lastarria, Francisco Bilbao y otros, que, a la par que ganaban connotación y renombre como Ministro, diputado, historiador, abogado u otro, según fuera el caso, crecían como figuras filosóficas. Luego, cabe decir que en un periodo de la historia de Chile en que un número importante de quienes gozaron efectivamente de la ciudadanía se dedicaba no tan sólo a pensar sino también a actuar ${ }^{3}$, Abasolo sólo pensó, pero sin consecuencias públicas. Dicho de otro modo, y en breve, el ámbito

1 Abasolo, agrimensor de profesión, ejerció un oficio considerado históricamente como de rango secundario: fue profesor de matemáticas por un corto periodo (del año 1859 hasta, quizás, mediados de la década de 1860) en el Colegio de Minería de Copiapó. Se puede ver el nombramiento de Abasolo como profesor del Estado, en Boletín de Instrucción Pública de Chile, año 1859, pág.511.

2 Actualmente, Jenaro Abasolo es considerado como «el más importante filósofo chileno del siglo XIX» (www.dibam.cl, sección Inicios y desarrollo de la Filosofía en ChileCronología), aunque su nombre es prácticamente desconocido para la historiografía nacional y no existan estudios que avalen dicha importancia. De donde la obra de Abasolo, con ser estimada de superlativo interés por instituciones oficiales del Estado, en los hechos resulta secundaria, marginal. Este asunto lo hemos denominado «El problema Abasolo», en Martínez \& Cordero, 2010: 93-95.

3 Domingo Benigno Cruz, deán de la Catedral de Concepción, critica mediante un libelo y, de paso, da testimonio de las consecuencias que podía tener para los autores, en este caso para Lastarria, la actuación en la vida política. Dice Cruz (1916: 53): «José Victorino Lastarria, Encargado Especial de Chile para arreglar nuestros límites con la República Argentina, cedió a ésta una parte de la Patagonia, hasta Cabo Blanco. La opinión pública se levantó contra él, se le declaró traidor a la Patria y se le obligó a renunciar a su honroso cargo, y poco después, cuando Manuel Bilbao, creyendo haber conmovido con sus escritos a esa misma opinión, vino a Chile a persuadirnos de la utilidad de ese límite, el pueblo de Santiago lo hizo huir a pedradas, y ni siquiera la Policía pudo detener los atentados contra ese pacificador». 
natural de Abasolo fue la política pensada, no la política vivida, por más que haya tenido algunas relaciones con autores como Lastarria y Sarmiento, y en su obra se prescriban los más altos fines sociales.

Ahora bien, aunque desde joven se caracterizó por un ferviente diletantismo en cuestiones de Estado, sociales y filosóficas, recién cuando contaba cerca de 28 años se registra el primer intento de acercamiento de Abasolo al foro, esto a través de su folleto anónimo Dos palabras sobre la América y su porvenir (1861). Los efectos de este escrito suyo y de los dos siguientes, también anónimos: La religión de un americano (1866), y Pobres y ricos (1872), como ha de suponerse ya, fueron nulos en la palestra intelectual de nuestro país. Tanto así que no se detecta reconocimiento alguno de la obra de Abasolo por parte de los autores nacionales de la época en que comunicó su pensamiento (Martínez \& Cordero, 2010: 91-107). Cuestión más que significativa, toda vez que por el contexto social y cultural de la época en que escribieron, el principal público lector de los autores - ya se tratare de chilenos en particular, o latinoamericanos en general - no fue otro que sus propios camaradas, es decir, «los mismos miembros de los cenáculos o los destinatarios extranjeros [de sus libros] a quienes fueron remitidos por cortesía» (Rama, 1984: 122-123).

Mas, creemos que también fue la propia personalidad de Abasolo la que contribuyó, en buena parte, para que sus coetáneos con similares intereses lo desconocieran como autoridad. Pues aún cuando el filósofo santiaguino en cierta medida coincidió en las temáticas y objetivos de los más revolucionarios autores chilenos de su tiempo - Lastarria y Bilbao, principalmente-, así como en los nombres fuente en que sustentó su crítica social y política - sobre todo Quinet, Michelet y Lamennais-, su vida se habría caracterizado por la excentricidad. De hecho, las escasas noticias biográficas detectables sobre Abasolo hablan de un hombre solitario, afectado por la neurastenia (Figueroa, 1925: 53), ocupado en múltiples labores, decepcionado de la naturaleza y sociedad europeas, y con una franca «repugnancia a todo aplauso y resonancia mundana» (Abasolo, 1907: IX-XIII). De donde cobra sentido la presentación tardía y anónima que hace el filósofo de sus librillos iniciales, y el hecho de que su cuarto texto, titulado La Personnalité (1877), y en el que sí estampó su nombre, lo haya escrito en francés y publicado en Bruselas - toda una osadía para la época, y aún hoy-, generando «juicios favorables de 
algunos pensadores» europeos (Figueroa, 1925: 53), entre los que destaca Félix Bovet ${ }^{4}$.

Consta La Personnalité - obra que en Chile corrió con la misma suerte que los anteriores textos de Abasolo, es decir, no tuvo eco alguno- de dos partes: La personalidad en si o la filosofía, y La personalidad social o los genios. A lo que habría que sumar — como el propio Abasolo señala (1877: 5) - una tercera parte, pendiente, titulada La personalidad política.

La obra póstuma de Abasolo (1907), nombrada La personalidad política y la América del porvenir, sería, precisamente, esa parte pendiente de $L a$ Personnalité, aunque con algunos aditivos difíciles de definir, dada la organización del texto. Por lo demás, es quizás con esta obra de principios del siglo XX, publicada por sus herederos, con la que hay una mayor identificación del nombre de Abasolo, aún cuando sean contados los que realmente la hayan leído. Julio César Jobet (1955: 55-56), la describe como «una obra densa, de lectura difícil», juicio que compartimos sólo relativamente.

Como sea que fuere, hemos de agregar que el libro en cuestión, ya valioso en sí, contiene en la Breve Reseña Biográfica firmada por la hija de Abasolo, a saber, la prosista y poeta Flora Abasolo - la más ferviente impulsora de la publicación de las obras de su padre (Castañeda, 2008: 163-164) - información significativa respecto de un Diario intimo y, sobre todo, de un manuscrito inédito titulado Estudio sobre la filosofía alemana, obra que Abasolo comenzó a escribir tal vez el año 1873, en Chile, y que habría concluido en su periplo por Europa. Este escrito - dice Flora (Abasolo, 1907: XIII) - comprendería tres partes: 1. Observaciones sobre la Critica de la razón pura de Kant, 2. Una hojeada sobre la destinación del hombre por Fichte; y 3. Sobre algunas ideas de Schelling acerca de la ciencia de la historia. Debiendo agregarse, también, el estudio titulado Observaciones sobre la lógica de Hegel. No obstante, y que se sepa, aparte de la información nominal dada por Flora Abasolo sobre estos manuscritos inéditos, «no hay otro testimonio» (Jobet, 1955: 49-50). Por lo tanto, la existencia de dichos manuscritos ha quedado en suspenso.

Ahora bien, tanto en su escrito del año 1877, como en el póstumo, de 1907, el discurso de Abasolo gira en torno al mismo objetivo, cual es "démontrer logiquement la responsabilité inaliénable de la conscience bumaine et la puissance supréme et primordiale de la volonté» (Abasolo, 1877: 5). Y esto teniendo el concepto personalidad como idea central y por ello convergente de su pensamiento. Aunque de distintos modos. Pues en el

4 Bovet, quien fuera Rector de la Universidad de Berna, instala el nombre de Abasolo en el Dictionnaire de français «Lé Litré», citando lo que el autor chileno expresa sobre el concepto unilatéral, precisamente en su obra La Personnalité (pág. 183). 
texto que el filósofo chileno publicó en Bélgica —un tratado de filosofía de carácter ético y psicológico que cuenta con permanentes alusiones a autores modernos, especialmente filósofos alemanes y franceses-, el concepto personalidad está más bien tácito que evidenciado o nombrado, esto no obstante el título del libro. En otras palabras, en La Personnalité Abasolo da cuenta, desde el punto de vista filosófico, de lo que estaría a la base de la necesidad de desarrollar las diferencias individuales que constituyen a cada persona, y que le posibilitarían el diferenciarse de las demás.

En cambio, en la obra publicada en Santiago por sus hijos, el concepto personalidad está patente y es recurrentemente utilizado; pero en referencia sobre todo a la política. De hecho, principia La personalidad politica y la América del porvenir - un verdadero tratado de filosofía socialcon una Introducción que pregunta ¿Qué cosa es la personalidad política? (Abasolo, 1907: 1), seguida por cinco libros en los que Abasolo despliega el concepto personalidad con un sello americanista y ribetes impensados en el medio nacional de la época.

«Hay la personalidad nacional y la personalidad individual —nos dice Abasolo-, y ambas se sostienen y compenetran». La primera «es la conciencia del pasado dirigida y juzgada por la conciencia del porvenir y por la idea del deber» (1907: 14). Mientras que la segunda, «es la conciencia de lo que somos juzgada por la conciencia de lo que debemos ser, proyectándose en la vida práctica como previsión y como elaboración del porvenir» (1907: 16). Luego, para Abasolo la personalidad es la capacidad del ser humano - como individuo y como ser social- de reconocerse en sus atributos esenciales, y en todas las modificaciones que en sí mismo experimenta. En Abasolo la personalidad es, entonces, conciencia: de lo bueno, de lo malo, de las cosas; conciencia de lo que se ha sido, de lo que se es y de lo que se debiera ser. Sin embargo, sostiene Abasolo (1907: 272) que «la personalidad humana no alcanzará su forma general definitiva, sino cuando cada energía individual, cada genio, cada aspiración del individuo, encuentren al nacer una esfera simpática de desenvolvimiento». Con lo cual el filósofo santiaguino nos advierte, a la vez, respecto de cuál ha de ser, por excelencia, el fin social: posibilitar las condiciones para que el hombre se transforme en un creador consciente de sí mismo y de los demás (Abasolo, 1907: 162), o lo que es igual, «hacer surgir las energías latentes de la personalidad hasta hacer que cada hombre se ponga enfrente de la sociedad como persona distinta [...] medio único de elevar la masa al rango de pueblo y de nación» (Abasolo, 1907: 10), y de propiciar, por ende, la más elevada sociabilidad.

De aquí, por extensión, cree Abasolo surgirán los nuevos mundos espirituales (1907: 9), esto es, aquellos mundos en los que todos los 
hombres se reconocerán como distintos pero en dependencia mutua. "Tout homme vit de la vie de plusieurs hommes et cette capacité est inépuisable et infinie et la vie devient une creátion perpétuelle», escribe Abasolo (1877: 37), resaltando de este modo el que cada hombre, inexorablemente, se desarrolla a partir de los otros hombres, lo que origina un estado de permanente re-creación social. En breve, ya que «cada hombre es la humanidad, conocida de un modo diverso» (Abasolo, 1907: 63), siempre el hombre tendrá material para crearse a sí mismo y para que los demás hombres creen a partir de él. La vida social aparece así, en Abasolo (1907: 81):

como una perpetua creación del hombre por el hombre, porque al concebir a los demás, no los concebimos servilmente, sino según nuestro tipo interior, y entonces la concepción toma la forma de un juicio. Al concebir, concebimos juzgando, y es este juicio incansable y perpetuo, ejerciéndose sin cesar en todo instante de las relaciones sociales, el que informa, corrige e incrementa el espíritu de los hombres.

De suerte tal que el fomento, cultivo y desarrollo de lo que en Abasolo significa la personalidad de tipo política, emerge como cuestión principal cuando de concretar los fines sociales se trata. Pues para el filósofo santiaguino es en virtud de la personalidad política, o sea, de la facultad trascendental, educable y progresiva ínsita en cada hombre, que puede crearse la sociedad futura (Abasolo, 1907: 1); sociedad en que, justamente, se les posibilitaría a los hombres el desplegar plenamente su potencia diferenciadora, esto es, su individualidad productora de sí mismo y de la sociedad. Por tanto, la acentuación y emergencia social de la personalidad de los hombres, pasa en Abasolo por el ejercicio efectivo de la actividad de la personalidad política, medio a través del cual pueden los seres humanos labrar su porvenir, según ideas racionales y preconcebidas.

Las Consideraciones socioeconómicas de que tratamos a continuación - extraídas todas del libro La personalidad política y la América del porvenir-, tienen, por ello, en Abasolo, el sentido último de probar que todo hombre está en posesión de la personalidad política; dan cuenta del camino que habría de seguirse para perfeccionarla indefinidamente; determinan, en fin, los medios más a propósito para alcanzarla.

\section{Economía normativa y religión}

Jenaro Abasolo muestra que el ilustre Lastarria, filósofo y político, cae en un error, 
cuando al clasificar las esferas de la actividad social señala la esfera industrial en globo, sin entrar a descomponerla en sus elementos necesarios: capital y trabajadores, propietarios y proletarios; como si creyera que lo positivo en esta esfera es la producción de la riqueza general y no la producción del hombre (Abasolo, 1907: 109) ${ }^{5}$.

Es decir, se equivoca Lastarria, tanto en reducir los agentes sociales, como en no subordinar la adquisición de riqueza a la expansión de la vida humana en todos los sentidos o, lo que es lo mismo, a su fin moral.

Creemos pues que Abasolo, con el juicio anterior, no sólo crítica el grueso análisis que realiza Lastarria del fenómeno económico, sino que, de pasada, reprueba el deficiente y casi nulo análisis ético-económico que los filósofos moralistas liberales chilenos, influenciados principalmente por las ideas de Courcelle-Seneuil (Hurtado, 2007: 1-8), han llevado a cabo.

Ciertamente, la importancia capital de la crítica de Abasolo a Lastarria, se cifra en que es el indicio inequívoco de la presencia en su filosofar de lo que actualmente se ha venido a llamar ética económica. Es decir, lleva a cabo una economía social constantemente atenta a revelar el nexo íntimo entre ética y economía.

Conforme a lo dicho, se evidencia a lo largo de la obra de Abasolo que la existencia de la miseria es la causa principal por la que la economía tiene que ser una disciplina prescriptiva, esto es, práctica. La economía debe establecer un deber ser, ha de plasmar una normatividad, que, como se dijo más arriba, exige tener como referente el fomento de la vida humana, pero, hay que añadir, que, para Abasolo, ésta necesita refrendar su orientación «en los principios constitucionales del Estado» (Abasolo, 1907: 95). Pues de otra forma el combate a la miseria puede convertirse en la batalla de un día, en un fin temporal y no en un esfuerzo permanente de una nación.

5 En efecto, Lastarria en la obra Derecho Público Consititucional realiza un análisis bastante general y breve de la esfera económica. Sin embargo, Lastarria en ese mismo escrito afirma: «Para evitar estas desgracias [aumento de la miseria de la población obrera y endeudamiento de los pequeños propietarios] es preciso que la industria reciba una organización que esté en más armonía con todos los intereses sociales y que guarde conformidad con el fin general de justicia cuyo intérprete es el Estado» (1906: 189). Teniendo presente estos juicios, es inadecuado afirmar que Lastarria no se preocupa de un fin social más allá de la producción de la riqueza. Hay que agregar, además, que él considera que el principio de libertad en la industria, debe tener un contrapeso, de otra forma tiene malos efectos. Es decir, para Lastarria (1906: 190) «es indispensable que el Estado haga respetar por los particulares y asociaciones los principios de justicia privada y social». 
Quinet, un referente constante del pensamiento decimonónico chileno, sostiene que el curso y despliegue de la Historia encuentra su fondo en «la idea religiosa» (Abasolo, 1907: 325). Es decir, para él, es claro que del principio religioso se deduce «la sociedad política y civil» (Quinet, s.d: v). A todas luces, Abasolo acepta esta idea al punto que gran parte de las tesis expuestas en la Personalidad politica tienen en ella su fundamento. Sin embargo, el filósofo chileno, además, transpone este principio de Quinet al ámbito económico en la medida en que explicita el nexo entre conducta económica y moral religiosa. Dicho de otro modo, entiende que las restricciones morales de una religión tienen un efecto eficaz en las decisiones económicas, pues, se deducen de ella. Como dijimos antes, a su entender, los principios constitucionales garantizan ciertas conductas económicas, pero, a la par, éstas pueden modificarse mediante

un cambio de religión que impusiese a los ricos deberes más eficaces y más humanitarios y diese a los pobres una noción más activa y más enérgica de sus derechos, manifestándose al exterior con la severidad de la dignidad ofendida, o por justas reclamaciones, y aun, por el desprecio hacia los ricos y hacia el clero, culpable de complicidad y negligencia (Abasolo, 1907: 95).

Luego, cierta religión puede promover una ciudadanía económica activa y el empoderamiento de las gentes en los asuntos que les afectan.

Una de las rutas seguidas para unir ética y economía ha sido intentar conectar la religión con el desarrollo económico. Es bien sabido que Weber explica (Troeltsch, 1951: 72) el desarrollo del capitalismo y, más aún, el surgimiento del espiritu del capitalismo desde la conciencia de un pueblo que ha sido educada en el calvinismo. Ciertamente, en Weber no existe la intención de fundar una ética económica a partir de esta constatación. Sin embargo, el economista James M. Buchanan usando el análisis de Weber, pero, pensando la religión más como un factor de fomento económico que como una explicación del origen de la economía, sí termina defendiendo una ética económica.

Abasolo es más simple y básico: ciertas restricciones normativas de orden religioso pueden limitar y evitar la explotación, la injusticia distributiva $y$, consecuentemente, pueden prevenir la miseria. La economía puede centrar y naturalizar su sentido desde una nueva religión, es decir, puede generar otro espíritu a nivel económico. Así pues, no es tanto el fomento de la riqueza o el ahorro lo que da valor a la ética presente en la religión, sino la posibilidad de impulsar el trabajo por el bien público y la justicia distributiva. Aunque, al igual que en Buchanan, esas restricciones éticas han de alcanzar el nivel constitucional o contractual, 
sobre todo cuando ciertas costumbres se han erosionado. De donde dice expresamente Abasolo (1907: 107) que, para torcer el rumbo de la economía moderna capitalista, «es menester cambiar radicalmente la carta constitucional».

El espiritu del capitalismo es reversible sin rehusar los progresos de la industria. Se trata, más bien, de poner las cosas en su lugar. Pues,

nadie podrá decir que por sí sean malos los progresos de la industria, pero son un objeto de perversión cuando se toman como agentes y como fines predominantes de la vida pública; porque entonces ellos hacen olvidar que hay en el hombre principios mucho más eminentes e inmutables que son los que deben constituir su felicidad verdadera y que han sido, en resumen, los principales motores que han impulsado al hombre a la investigación y al hallazgo de esos secretos científicos e industriales que ahora pretenden suplantarlos (Abasolo, 1907: 106).

Los hallazgos de la industria han de ser dirigidos entonces desde otro espiritu. El espíritu capitalista, que en parte hace presa al propio Lastarria, centrado tan sólo en la riqueza, debe ser reemplazado por aquel que se ocupa de la persona del industrial y del proletario.

\section{El dogma de la respetabilidad de la riqueza}

Abasolo desacredita completamente esa libertad que sólo se consuma en la competencia, en la iniciativa económica y en la producción de riqueza. Para él, al reducir la libertad a la no-interferencia en el emprendimiento económico, «se injuria a la moral, a la razón y al infortunio» (Abasolo, 1907: 87). Partimos de un principio que «produce en la sociedad la gran desproporción en el reparto de la fortuna» y que, además, le da carta de ciudadanía a esta iniquidad. Conjuntamente, aparece el culto a la riqueza que es, como señala insistentemente Abasolo, la raíz del decaimiento moral de una nación. Esta falta de moralidad se manifiesta en la pauperofobia y en el desplazamiento de la dignidad a la posesión. Si la pobreza es vergüenza y el dominio del capital motivo de jactancia, «¿cómo no combatir entonces a capa y espada por esa riqueza que redime de la ignominia y que nos colma de honores?» (Absolo, 1907: 88).

Para el filósofo santiaguino, una sociedad estructurada sobre «el dogma de la respetabilidad de la riqueza» (Abasolo, 1907: 88) abjura de su verdadero fin que es «el engrandecimiento de su ser moral» (Abasolo, 1907: 221; Martínez \& Cordero, 2010: 101). Primeramente son ciertos 
individuos los que desvían sus tendencias del verdadero fin, luego, la sociedad y la política toman el mismo rumbo torcido. Para él, si de este orden de cosas nace algo parecido a una aristocracia, ésta no será más que un estamento de pulperos y comerciantes, es decir, una «aristocracia rapaz» (Abasolo, 1907: 89).

Abasolo acepta que puede disminuir la miseria del pobre sin que la opulencia del rico disminuya, pero pese a esta posibilidad, considera que el problema económico no se resuelve. En efecto, alguien podría argumentar que no hay necesidad de rasgar vestiduras y de cloquear tanto, cuando acontece que los ricos pueden mantener su opulencia sin que esto signifique restar a los demás del goce de la riqueza: basta un poco de emprendimiento de parte del pobre y problema resuelto. Sin embargo, ocurre que, según piensa Abasolo, el problema radica en que ese estado de cosas a nivel social produce, como hemos señalado, un sentimiento de estimación respecto a la riqueza que es funesto para la vida moral y política. En efecto, para el pensador chileno la desnaturalización de los fines sociales no proviene de la desproporción de las fortunas en sí misma, «sino del culto que se le rinde y del desden que acompaña al pobre» (Abasolo, 1907: 93). Es decir, al olvidar que la riqueza está subordinada a fines sociales, se genera un sistema en el cual las codicias aumentan y la insatisfacción se desata.

Se advierte que Abasolo, como todo aquel que plantea una ética económica, considera que el arte adquisitivo ha de tener un fin externo a sí mismo que le sirva de límite. Sin este límite tenemos una economía desvirtuada. Aristóteles como iniciador del enfoque ético de la economía, consideraba que no podemos confundir el arte adquisitivo (crematística) con la economía. La economía es una disciplina esencialmente práctica, ética, porque es, en última instancia, para la vida buena de la comunidad. La economía por tanto debe acotar el deseo ilimitado respetando el trazado que marcan las necesidades humanas.

Abasolo coincidiría, en buena parte, con el filósofo griego diciendo que la riqueza está subordinada al fin de la vida humana, lo que en el autor de la Personalidad política significa la perfección manifestada en la expansión e intensificación de la vida misma ${ }^{6}$. Pero, además, agregará que

6 Ciertamente, el fin de la vida humana entendido como expansión, sociabilidad y extensión que es defendido de forma vehemente por Abasolo, se encuentra ya en Lastarria. Sin duda, éste autor es la fuente más directa de Abasolo, tal como lo son parte de sus lecturas francesas. Por lo mismo, téngase presente el siguiente texto de Lastarria (1906: 29-30): «El bien del hombre consiste en el desarrollo de sus facultades y de sus relaciones con el orden general de los seres del universo, porque está destinado a desenvolverse sucesivamente por su propia naturaleza; y así su fin racional no puede consistir en otra cosa que en la perfección y extensión de esas mismas facultades y esas 
la economía no se puede reducir al análisis económico, ni a las cifras. Dice Abasolo:

Las cifras totales de la producción no valen nada por sí mismas sino por su relación con este problema, el cual es el único aspecto positivo de la esfera económica, por cuanto no sólo atañe a un principio de justicia y de humanidad, sino como hemos dicho a la felicidad o a la ruina de las naciones (Abasolo, 1907: 109; Martínez \& Cordero, 2010: 108).

\section{Sobriedad y economía}

Un pueblo obsesionado por la riqueza no puede valorar la vida sobria y menos considerarla como un ideal de vida. Pero, ¿se puede buscar la sobriedad en un sistema económico capitalista? El modelo humano del emprendedor que, según Sombart, cuaja con él, ¿puede ser sobrio?

Los análisis de Weber, Sombart y Troeltsch, muestran que la economía es el gran motor de la vida social, pero esto no significa que ésta no haya devenido de un espíritu. La modalidad de economía, sin duda, ampara y promueve un espíritu, mas esto no significa que, en un comienzo, ella no deba su génesis al modo de valorar del sujeto. Justamente, tras la economía capitalista hay un espíritu que es el de aquel que pone a la voluntad de poder al servicio de sí misma. Como muestra Sombart, el espíritu emprendedor que se manifiesta en el Estado, en la religión, en la Iglesia, «comienza a dominar también la vida económica, y, en efecto, derriba las barreras de la economía meramente limitada a la satisfacción de las necesidades, economía basada en la sobriedad, mantenida siempre en equilibrio, estática, feudal, artesana, y empuja a los hombres hacia la vorágine de la economía lucrativa» (Sombart, 1931: 79). Por tanto, hay en la trastienda de la economía una vida afectiva que valora, un pathos peculiar, que hace evidente el primado de la moral en todas las esferas de la vida humana. En las conductas económicas adversas a la plenitud de los pueblos está operando, no sólo la economía por sí misma, sino, también, las más de las veces, los chicos malos de la economía. Es decir, individuos deseducados muchas veces en las escuelas de negocios y, por lo mismo, actuando desde una específica moralidad. La trascendencia del carácter educado del individuo es indudable para el filósofo santiaguino, a tal grado que expresa que «los grandes hombres

relaciones con sus semejantes, con el orden natural y con el Ser supremo [...] no se puede concebir otro fin en el hombre que el desarrollo continuo de su naturaleza interior y el engrandecimiento constante del círculo de su vida». 
crean el mundo de modo grande y los miserables de un modo miserable» (Abasolo, 1907: 443).

En consecuencia, la pregunta no es qué hacer en economía, sino qué hacer con ese espíritu voraz que rige su destino. Sin duda, se necesita una economía política para esclarecer el fin moral de la economía, pero, por sobre todo, un cambio de espíritu mediante la educación. Para Abasolo, es claro «que un pequeño cambio en la esfera espiritual vale más que todos los recursos de la economía política, la cual sólo debe ser un pequeño suburbio de la moral» (Abasolo, 1907: 442).

Tomando un prisma que se fortalece por una larga tradición de pensadores, entre los que destaca Rousseau, Abasolo considera que el lujo no es indicio de florecimiento, sino, más bien, de decadencia ${ }^{7}$. El filósofo chileno cifra la posibilidad de una sociedad más justa en «la ignorancia de las comodidades del lujo» y en «la ilustración impuesta por la educación obligatoria» (Abasolo, 1907: 102). De ellas resultan hábitos de economia que son posibles gracias a la temperancia y la sobriedad. Al entender de Abasolo (1907: 442), el rico se haría más desprendido y el pobre podría constituirse en un pequeño propietario debido a la adquisición de una disposición al ahorro. Sin duda en el oído de Abasolo resuena el eco de las evangélicas palabras de Lamennais (1945: 50): «Con poco vive el hombre, que tan poco tiempo ha de vivir». Así, también, Abasolo parece decir con Aristóteles (en Protréptico 4): «la saciedad cría insolencia, y la falta de educación con poder, insensatez».

\section{Ley y libertad republicana}

Los románticos sociales, de los cuales creemos forma parte Abasolo, se dan cuenta que el espíritu emprendedor no es un espíritu que desarrolle eficazmente su henchimiento sin poner a la ley de su lado. Ya Rousseau afirmaba con claridad que el rico tiende a elevar sus prerrogativas al plano de las leyes. Lamennais se encamina a afirmar algo similar al ginebrino cuando se pregunta: «¿De dónde proviene la riqueza de algunas clases?». Él mismo responde que su origen es «la miseria de las otras; de que en virtud de las leyes hechas por el rico para el interés exclusivo del rico, casi él solo se aprovecha del trabajo del pobre»

\footnotetext{
7 Dice Rousseau (2003: 93): «[...] finalmente [para que funcione el gobierno democrático] poco o nada de lujo, porque o el lujo es efecto de las riquezas, o las hace necesarias; corrompe a la vez al rico y al pobre; al uno por posesión y al otro por ambición; vende la patria a la molicie, a la vanidad; priva al Estado de todos sus ciudadanos para hacerlos esclavos unos de otros, y todos de la opinión».
} 
(Lamennais, 1945: 128). Con esta afirmación patética, Lamennais muestra cómo la ley tiene un efecto poderoso en la empresa de mantener la sujeción y un estado de cosas. En otras palabras, a la ley que debiera ser el lugar de la ausencia de arbitrariedad, se la pone al servicio de la voluntad de poder, de la pleonexía de aquel que más posee. Según Abasolo (1907: 114), hay un «pacto maldito», un «pacto satánico», «que mantiene atado en los limbos de abajo esa gran mayoría del género humano que se llama peón, obrero, sirviente, mendigo, raza de desheredados, sin personería y sin personalidad $[\ldots] »$.

El ilustrado confía en que si hay un momento incondicionado, un momento de verdadera igualdad, ese será el que concede la ley. Ciertamente, para que esto sea así debe ser legítima, es decir, verdadera ley. Justamente, la razón por la cual el ilustrado respeta y venera la ley se debe a que representa el momento de la igualdad. Nos parece que este respeto a la ley que se evidencia en Abasolo, permite que en su persona se sinteticen los rasgos románticos con los ilustrados de un modo semejante a como acontece en Rousseau.

El romanticismo de Abasolo, como epígono de Quinet, Lamennais, Michelet, entre otros, no considera que la ley sea una traba o el momento de heteronomía, sino a la inversa. Al tener esta forma de ver, todos los autores mencionados son rusoneanos. Ya hacía ver Cassirer (2007: 75) que, según el entender del ginebrino, la ley no me «obliga a reptar como un caracol» como creen algunos románticos. Ciertamente, los que respiran en la atmosfera del Sturm und Drang oponen libertad y ley, pero, en caso alguno, ésta es la «disposición intelectual y moral de Rousseau». Es la ley la que sobrepasa las «voluntades individuales»y, por ello, es «el lugar de lo que todos podríamos querer». El mismo Lamennais (1945: 39), sin dejar su tono mesiánico expresa dirigiéndose al pueblo: «No os crió Dios para que fueseis rebaño de algunos hombres. Os crió para que fueseis libres, en sociedad, como hermanos; y el hermano no tiene derecho para imponer su voluntad a su hermano. Los hermanos se unen entre sí por convenios recíprocos, y esos convenios son los únicos que tienen fuerza de ley; y esta ley es la que deben respetar e impedir que sea violada, porque es la salvaguardia de todos, la voluntad y el interés de todos».

En concordancia con esto, Abasolo estima que el ejercicio de la «ciudadanía económica» se vuelve imposible sin una legislación en la que hayan participado en su constitución, justamente, los que «sufren» con las decisiones económicas (Martínez \& Cordero, 2010: 108). El Estado debe regular desde una legislación establecida por los afectados. Sostiene Abasolo (1907: 110) que «si el fin del Estado es inculcar o aplicar el 
derecho, es su deber injerirse allí donde hay robo o una expropiación evidentemente demostrados, a fin de corregirlos». Es decir,

si en la sociedad hay una esfera que se llama industrial, en la cual se consuma una iniquidad progresiva, el Estado debe injerirse en ella a fin de remediarla como se injiere en las demás esferas, cuando conculcan el derecho (Abasolo, 1907: 110ss.).

El Estado debe ser redistributivo, por ello, opina Abasolo (1907: 156), que «el rico no debe gozar tranquilamente de toda su riqueza y el Estado debe gravarlo en la proporción que sea necesario, a fin de ocurrir a la redención del pueblo desheredado». Es tarea del Estado, entonces, amparar la libertad de no-dominación (libertad política) y, por lo mismo, ha de asegurar un mínimo de posesión a los ciudadanos. Este es un requisito ineludible para el ejercicio de la vida republicana. En otras palabras, la libertad para todos requiere de un mínimo de propiedad que permita independencia y que nadie pueda hacerse dueño del otro. Aquella libertad que sólo encuentra su límite en el no dañar directamente al prójimo, no sólo da cabida a la opresión de unos sobre los demás y al daño indirecto, sino que, por lo anterior, su ejercicio tiende a ser privilegio de pocos. Sostiene Abasolo (1907: 52):

El principio de la libertad individual, aunque le asignen un límite, el de no ejercerla en perjuicio directo de la del vecino, ese es un límite bien indeterminado que puede llevar la libertad individual hasta dejar a la sociedad a merced de un centenar de propietarios y de usureros, si se sigue interpretando el principio como se ha hecho hasta ahora.

Abasolo está hablando de esa libertad que, si bien permite el despliegue del deseo individual, también, termina socavando la justicia y la cohesión social. En cambio, su contraparte, «la libertad republicana», requiere de «la fraternidad y la amistad progresiva» (Abasolo, 1907: 89). Como ha señalado Sen (1997: 123) en nuestro tiempo, a pesar de que «a menudo se utilizan de un modo enérgico el lenguaje y la retórica de la libertad para defender el mecanismo de mercado, por ejemplo, en la forma de la tesis de que el sistema de mercado hace a las personas libres para elegir», difícilmente podemos llegar a identificar esta posibilidad con la libertad política. La libertad no puede desentenderse, según Abasolo, de una potencia «estética creciente» que nos permita la comprensión del otro; para decirlo con Nietzsche, es menester sentir cósmicamente. Dice Abasolo (1907: 81): 
En efecto, comprender a los demás y sentir lo que ellos sienten es sentir muchas vidas diversas a la vez unidas en una sola, y es esa unidad estética la que nos procura la mayor potencia intelectual y moral.

En definitiva, la libertad, que es siempre libertad en la comunidad, no puede existir si no hay sensibilidad respecto del otro.

\section{REFERENCIAS}

-Abasolo, J. (1907). La personalidad política y la América del porvenir. Santiago de Chile: Imprenta y Encuadernación Universitaria.

-Abasolo, J. (1877). La Personnalité (F. Cordero et. al., Trads.). Bruxelles: Typographie V.Ch. Vanderauwera.

-Abasolo, J. (1861). Dos palabras sobre América y su porvenir. Santiago de Chile: Imprenta Chile.

-Abasolo, J. (1866). La religión de un americano. Santiago de Chile: Imprenta Unión Americana.

-Abasolo, J. (1872). Pobres y ricos. Santiago de Chile: s/n.

-Cassirer, E. (2007). Rousseau, Kant, Goethe. Filosofía y cultura en la Europa del siglo de las luces. México, D.F.: Fondo de Cultura Económica.

-Castañeda, P. (2008). Unamuno y las mujeres. Madrid: Visión Libros.

-Cruz, B.-D. (1916). La glorificación de D. José Victorino Lastarria y de sus doctrinas. Santiago de Chile: Imprenta Chile.

-Figueroa, V. (1925). Diccionario histórico y biográfico de Chile. 1800-1925. Santiago de Chile: Imprenta y Litografía La Ilustración.

-Hurtado, C. (2007). La recepción de Courcell-Senueil, seguidor de Tocqueville, en Chile. Polis (5), 1-8.

-Jobet, J. (1955). Precursores del pensamiento social de Chile. Santiago de Chile: Editorial Universitaria.

-Lamennais, F-R. (1945). Palabras de un creyente. Buenos Aires: Partenón.

-Lastarria, J-V. (1906). Obras completas. Santiago de Chile: Imprenta, Litografía y Encuadernación Barcelona.

-Martínez, P. \& Cordero, F. (2010). Jenaro Abasolo. Esbozo de su pensamiento. Filosofía, Educación y Cultura (10), 91-108.

-Quinet, E. (s.d). El genio de las religiones. Valencia: Sempere y Compañía.

-Rama, Á. (1984). La ciudad letrada. Hanover: Ediciones Norte.

-Rousseau, J. J. (2003). Del contrato social. Sobre las ciencias y las artes. Sobre el origen y los fundamentos de la desigualdad entre los hombres. Madrid: Alianza.

-Salazar, G. \& Pinto, J. (1999). Historia contemporánea de Chile I. Estado, legitimidad y ciudadania. Santiago de Chile: LOM Ediciones.

-Sen, A. (1997). Bienestar, justicia y mercado. Barcelona: Paidós.

-Sombart, W. (1931). La industria. Buenos Aires: Labor.

-Troeltsch, E. (1951). El protestantismo y el mundo moderno. México, D.F.: Fondo de Cultura Económica. 
Sumario: Introducción; 1. Economía normativa y religión; 2. El dogma de la respetabilidad de la riqueza; 3. Sobriedad y economía; 4. Ley y libertad republicana; Referencias. 